\title{
Bilateral Hip Resection for Closure of Trochanteric Pressure Sores: Case Report
}

Amiram Sagi, M.D., ${ }^{1}$ Yitzhak Meller, M.D., ${ }^{2}$ Moshe Kon, M.D., Ph.D., ${ }^{1}$ Lior Rosenberg, M.D., ${ }^{1}$ and Yona Ben-Yakar, M.D. ${ }^{1}$

Departments of Plastic and Reconstructive Surgery ${ }^{1}$ and Orthopaedics ${ }^{2}$ Soroka University Hospital and Faculty of Health Sciences, Ben-Gurion University of the Negev, Beer-Sheva, Israel

\section{Summary}

Bilateral resection of the proximal femur, an orthopaedic procedure advocated in selected cases of infected hip joints, can be useful in the treatment of extensive pressure sores in paraplegics. It is especially indicated in those cases where a total thigh flap is considered with the advantage of saving the limb, and by shortening the leg providing more skin and soft tissue for closure of the pressure sores.

Key words: Paraplegia; Trochanteric pressure sore; Bilateral hip resection.

Pressure sores are a troublesome problem for paraplegics and a great challenge for the surgeon. They usually develop from prolonged compression of the skin and subcutaneous tissues between a bony prominence and the bed or chair. It is essential to remove this prominence thoroughly in any attempt to treat these wounds surgically (Campbell and Delgado, 1977; Griffith, 1979). Considering trochanteric pressure sores this is done by removal of the greater trochanter and the upper lateral cortex of the femur shaft (Campbell and Delgado, 1977; Griffith, 1979). We describe herein a case with multiple extensive ducubitus ulcers in a wheelchair-bound paraplegic where we performed a bilateral hip resection to facilitate closure of huge trochanteric pressure sores and at the same time gaining more tissue for closure of other defects.

\section{Case Report}

A 16-year-old paraplegic Bedouin boy was admitted to our department because of multiple huge pressure sores (Fig. 1). He became paraplegic after a road accident 4 years earlier, when he sustained multiple injuries including a fracture-dislocation of the spine at L4-5 level, and he required a splenectomy.

During the last 2 years he was admitted several times to our department because of recurrent pressure sores that were treated with skin grafts or local skin flaps.

On admission the patient looked severely ill, cahectic and pale. His tempera- 


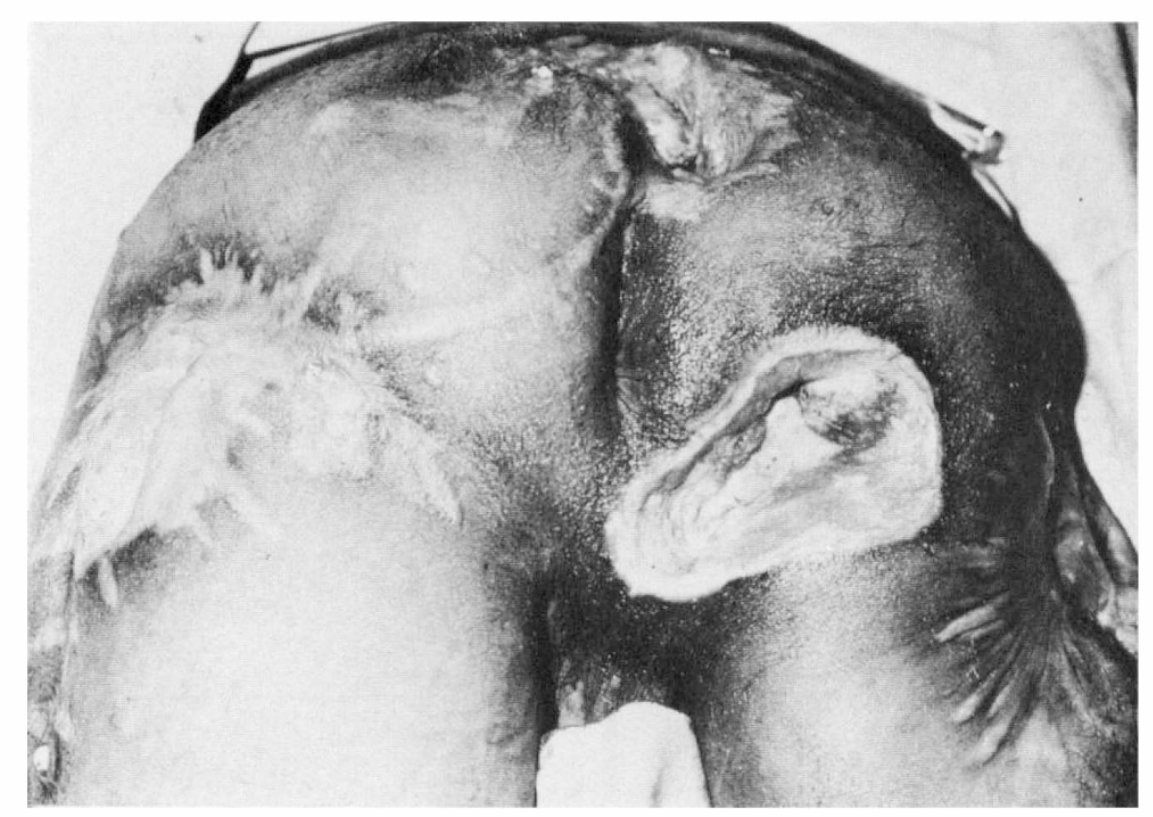

Figure 1 Pre-operative view: sacral, bilateral trochanteric and right ischial pressure sores. Note extensive scarring from previous operations.

ture was $39^{\circ} \mathrm{C}$. Physical examination revealed huge necrotic pressure sores on the sacrum, right ischial tuberosity and both greater trochanters. Minor wounds were noticed on the right knee and heel. Urine sediment was full of leukocytes and urine culture revealed escherichia coli.

Chest X-rays were normal. Radiography of the pelvis revealed a paralytic scoliosis of the lumbar spine and an old, severely displaced fracture of the upper left femur with non-union. There were signs of osteomyelitis and septic arthritis of the left hip.

After stabilising the patient in a better nutritional condition we performed en bloc excision of both trochanteric pressure sores with surrounding scar and underlying bursa in combination with bilateral hip resection. By removing the infected proximal femur together with all the disturbing bony prominences on both sides we were able to approximate the trochanteric wounds with ease. Garamycin beads-Septopal (Grieben, 1980) were left at the site of operation to combat possible infection. The remaining pressure sores were closed later in two stages using glutexus maximum musculocutaneous flaps for closure of the sacral decubitus, a semimembranosus-semitendinosus musculocutaneous flap for the right ischium and a biceps femoris musculocutaneous flap to supply a better cover for the area of the left trochanteric wound. In the latter two operations the V-Y advancement principle was used (Hagerty, 1980; Hurteau et al., 1981; Scheflan, 1982; Tobin et al., 1981). The minor wounds of the knee and heel were treated with skin grafts.

At present 2 years after the last operation all wounds are closed (Fig. 2). There is a pseudoarthrosis of both hip joints (Fig. 3) that enables the patient to use his wheelchair comfortably. Daily the patient travels between his tribe in 


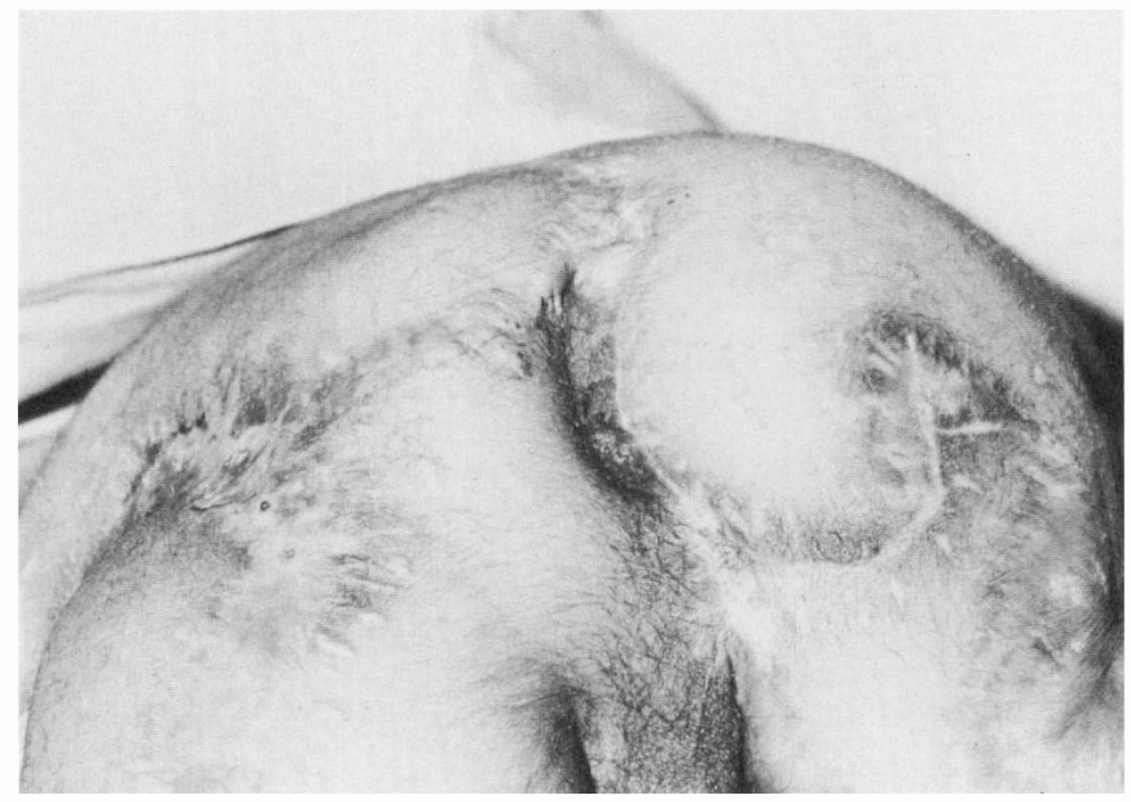

Figure 2 Patient 2 years' postoperatively. Wounds are closed except for small excoriation on the right side that was spontaneously healed.

the Negev desert and Beer-Sheva, a distance of 18 kilometres, to attend high school classes. Originally rejected by his tribe, he is now fully accepted and taken care of in a proper way, which is of utmost importance in the prevention of new pressure sores.

\section{Discussion}

Since surgery was first applied for the repair of pressure sores in 1945, many different methods have been described to conquer this often extensive wound. The various musculocutaneous flaps commonly used to date, are very reliable and give a stable, soft tissue padding over the areas where bony prominences are removed (Hagerty, 1980; Hurteau et al., 1981; Scheflan, 1982; Tobin et al., 1981).

In general, these areas are: (1) Medial and lateral sacral crests, the posterior superior iliac spines and the coccyx for sacral ulcers; (2) The ischium-totally or partially-for ischial ulcer and (3) The greater trochanter for trochanteric ulcers (Campbell and Delgado, 1977; Griffith, 1979). Only when extensive ulceration is present and no flap cover is possible, salvation surgery using a total thigh flap after amputation of the extremity, is the method of choice (Georgiade et al., 1956; Royer et al., 1969; Spira and Hardy, 1963; Weeks and Brower, 1968).

Indications for this extensive operation as mentioned by Royer et al (1969) are (a) multiple or recurrent ulcers with insufficient adjacent tissues; (b) large trochanteric ulcers complicated by pyoarthrosis and/or osteomyelitis of the femur; (c) multiple ulcers with ankylosed hip or knee joints; (d) single ulcers too 


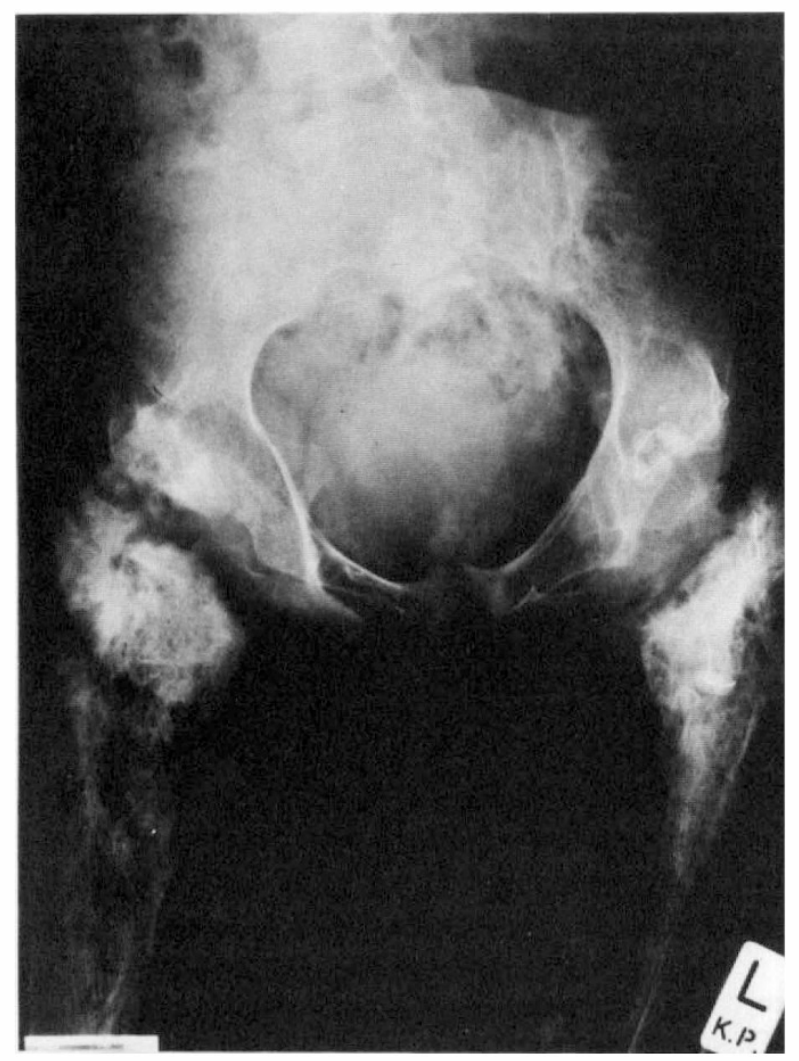

Figure 3 Post-operative A-P radiograph shows both upper femurs after resection of both hips and upper third of femurs. Chain of garamycin beads in situ.

large to be covered by rotation flaps and (e) ulcers with associated pelvic osteomyelitis.

It can be seen that our patient had good indications for such an operation especially with his non-united old fracture of the left femur, its displaced bone ends as an extra site of pressure, the osteomyelitis and the extensive soft tissue defects. Because of the patient's and his family's objection (disfiguration in some Bedouin tribes is unacceptable), his young age, and the rehabilitation potential to be lost by sacrificing a limb, we finally decided to perform a bilateral hip resection. This operation was first suggested by Guttman was a treatment for severe cases of pyoarthrosis and osteomyelitis of the hip joint in paraplegics (Guttmann, 1953; Guttmann, 1973). Its advantages in treating the pressure sore itself were, to the best of our knowledge, overlooked. By shortening the femurs we removed the infected joint and the bony prominences that caused the wounds. At the same time, we gained more skin and muscle tissue-though atrophic in part-for closure and support. In our case, closure of the ischial wound at a later stage, with a musculocutaneous flap, using the V-Y advancement principle was therefore facilitated (Hagerty, 1980; Hurteau et al., 1981; Scheflan, 1982; Tobin et al., 1981). As we wanted to change the vulnerable skin cover of the left trochanteric site, we could perform a V-Y biceps musculocut- 
aneous advancement flap in an already healed area, without the risk of dehiscence due to infection or tension. Patients after hip resection develop flail hipa fibrous pseudoarthrosis which gives quite a reasonable range of motion (Guttmann, 1953; Guttmann, 1973). It should be remembered that paraplegic patients bound to wheelchairs do not need more than such a hip, and also in our patient this end result was fully acceptable.

The use of this orthopaedic procedure in the aid of treating pressure sores has the same indications as for the total thigh flap (Royer et al., 1969), with the great advantage of saving the limb. Without the bony prominences of the proximal femur and the remaining part buried inside the muscles, it is unlikely to have a recurrency at the previous site of the trochanters, but for the pessimists, a total thigh flap can still be done.

\section{References}

Campbell RM, Delgado JP 1977 The pressure sore. In: Convers JM (ed): Reconstructive Plastic Surgery, Ed 2, Philadelphia, WB Saunders Company, pp. 3763-3799.

Georgiade N, Pickrell K, Maguire C 1956 Total thigh flaps for extensive decubitus ulcer. Plastic and Reconstructive Surgery 17:220.

GrIEBEN A 1980 Clinical results of Septopal $^{\mathrm{R}}$ in bone and soft tissue infections: A survey of clinical trials. In: local antibiotic treatment in osteomyelitis and soft tissue infections. Proceedings of the Symposium, Amsterdam, Excerpta Medica, Int. Congress series 556: pp. 120-128.

GRIfFITH BH 1979 Pressure sores. In: Grabb WC, Smith JW (eds) Plastic Surgery. Ed 3, Boston, Little, Brown and Company, pp. 818-825.

GUTTMANN L 1953 The treatment and rehabilitation of patients with injuries of the spinal cord. In: MacNalty AS, Cope Z (eds) Brit History of World War II, Surgery, HM Stationary Office, London, pp. 486-496.

Guttmann L 1973 Spinal cord injuries. Ed 1, Oxford-London, Blackwell Scientific Publications, 1973, pp. 509-511.

HAGERTY RF, HAGERTY RC, HAGERTY HF 1980 The hamstring myocutaneous flap in repair of ischial decubiti. Annals of Plastic Surgery 5:227-231.

Hurteau JE, Bostwick J, Nahai F, Hester R, Jurkiewicz MJ 1981 V-Y advancement of hamstring musculocutaneous flap for coverage of ischial pressure sores. Plastic and Reconstructive Surgery 68:539-542.

Royer J, Pickrell K, Georgiade N, MLadick R, Thorne F 1969 Total thigh flaps for extensive decubitus ulcers. A 16-year review of 41 total thigh flaps. Plastic and Reconstructive Surgery 44:109-118.

SCHEFLAN M 1982 Surgical methods for managing ischial pressure wounds. Ann Plast Surg 8:238247.

SPIRA M, HARDY SB 1963 Our experience with high thigh amputation in paraplegics. Plastic and Reconstructive Surgery 31:344-352.

ToBIN GR, SANDERS BP, MAN D, WEINER LJ 1981 The biceps femoris myocutaneous advancement flap: a useful modification for ischial pressure ulcer reconstruction. Annals of Plastic Surgery 6:396-401.

WEEKS PM, BROWER TD 1968 Island flap coverage of extensive decubitus ulcers. Plastic and Reconstructive Surgery 42:433-436. 